\title{
UTILIZATION OF MATERNAL AND CHILD HEALTH SERVICES AMONG WOMEN ADMITTED IN MATERNITY WARD OF A HOSPITAL OF SIDDHARTHANAGAR MUNICIPALITY
}

\author{
Binita Khatri, ${ }^{1}$ Saraj Gurung, ${ }^{1}$ Anuja Kachapati ${ }^{1}$
}

\section{ABSTRACT}

\section{INTRODUCTION}

Maternal and child mortality is a global issue which could be prevented by the utilization of maternal and child health $(\mathrm{MCH})$ services. The main objective of this study was to find out the utilization of MCH services among women admitted in maternity ward of a hospital.

\section{MATERIAL AND METHODS}

Cross-sectional descriptive study was conducted to find out the utilization of $\mathrm{MCH}$ services among 150 women admitted in maternity ward of a hospital. Non-probability purposive sampling technique was used to select the sample and semistructured interview schedule was used to collect the data and collected data was analyzed with SPSS version 16.

\section{RESULTS}

The study showed that $100 \%$ of the women had utilized antenatal services, $98.67 \%$ delivered their baby in health centres and utilized postnatal services. During pregnancy, women got health education on danger signs (66.67\%), avoidance of sexual intercourse (54\%), and birth preparedness (44\%). Cent percent of the children utilized at least one child health services, $80 \%$ were breastfed within hour of birth, and $93.24 \%$ of women were not aware of administration of vitamin K to their newborn. Ethnicity, religion, education, occupation, age at marriage, gravida, parity, history of abortion or child death and number of live children of women, education and occupation of spouses were significantly associated $(p<0.05)$ with utilization of maternal health services.

\section{CONCLUSION}

It is recommended that nurses and health personnel should provide health education focusing on birth preparedness, danger signs of mother and baby, and should inform about administration of vitamin $\mathrm{K}$ to mother.

\section{KEYWORDS}

Child health services, Maternity, Maternal health services, Utilization.

1. Universal College of Nursing Sciences, Bhairahawa, Nepal

DOI: http//doi.org/10.3126/jucms.v9i01.37985

For Correspondence

Ms. Binita Khatri

Universal College of Nursing Sciences

UCMS, Bhairahawa, Nepal

Email:binukanchi91@gmail.com 


\section{INTRODUCTION}

Globally about 295,000 women died during and following pregnancy and childbirth in 2017. The majority of these deaths (94\%) occurred in low-resource settings, and most could have been prevented. 'Sub-Saharan Africa and Southern Asia accounted for approximately $86 \%$ of the estimated global maternal deaths in 2017. Southern Asia accounted for nearly one-fifth $(19.66 \%)^{2}$

The high maternal and neonatal mortality rates in South Asia and Sub-Saharan Africa can be contributed to the lack of health services for delivery. A study from the Department of Health Services conducted in Bangladesh, India, Pakistan, Kenya, Nigeria, and Tanzania shows more than half of the births in these countries were delivered outside a health facility and within each countries, the poorer, less educated and rural women had higher unmet need for maternal care services. ${ }^{3}$ The maternal mortality ratio in Nepal decreased from 539 maternal deaths per 100,000 live births to 239 maternal deaths per 100,000 live births between 1996 and 2016. In 2016, roughly $12 \%$ of deaths among women of reproductive age were classified as maternal deaths. ${ }^{4}$

Maternal health is the health of women during pregnancy, childbirth and the postpartum period and maternal health care services are antenatal care (ANC), delivery care and postnatal care (PNC) services. ${ }^{5}$ Early and frequent ANC attendance during pregnancy is important to identify and mitigate risk factors in pregnancy and to encourage women to have a skilled attendant at childbirth. Postnatal care improves the health of both the newborn and mother.

Objectives of this study was to find out the utilization of $\mathrm{MCH}$ services among women admitted in maternity ward and to identify the association between socio-demographic variables with utilization of maternal health services.

\section{MATERIALAND METHODS}

A cross-sectional descriptive research design was conducted to find out the utilization of $\mathrm{MCH}$ services among women admitted in maternity ward of a Universal College of Medical Sciences -Teaching Hospital (UCMS-TH) of Siddharthanagar Municipality, Nepal. Population of the study was all the multiparous women admitted in postnatal ward of UCMS-TH and had given birth within last three years preceding date of data collection.

Sample size was calculated based on Slovin's formula $[n=N /$ $\left.1+\mathrm{N}(\mathrm{e})^{2}\right]$ where, $\mathrm{n}=$ number of samples, $\mathrm{N}=$ total population (206 multi-mothers in a month), e = margin of error (0.05). Assuming 10\% non-response rate total sample size was 150 . Non-probability purposive sampling technique was used for sample selection. Semi structured interview schedule was used for data collection from 10 July to 10 September, 2020. A descriptive statistics and inferential statistics (chi-square tests) were used to find out the association between socio- demographic variables with utilization of maternal health services with SPSS version 16. Ethical and administrative approval was obtained from the concerned authorities prior to data collection. Written informed consent was obtained from each respondent by clarifying the objective of the study.

\section{RESULTS}

Regarding socio-demographic variables of respondents, $48.67 \%$ were between age group of 25-29 years. Regarding ethnicity, $40 \%$ were Madhesi and $66 \%$ respondents belong to Hindu religion. About $41 \%$ of respondents can read and write and $26 \%$ of the respondents were engaged in services. Fortysix percentage of respondents got married at the age of 15-18 years. About $55.33 \%$ of the respondents live in joint family and $17.36 \%$ of the respondents had abortion or child death and $66 \%$ of the respondents had two children.

Regarding respondents' spouses, 50\% were between 26-30 years of age, $42.67 \%$ could read and write, $31.33 \%$ were service holder and $90.67 \%$ of respondent's spouses were involved in family decision making.

Table 1. Utilization of antenatal services $(\mathbf{n}=\mathbf{1 5 0})$

\begin{tabular}{lcc}
\hline Variables & Frequency & Percentage \\
\hline Frequency & 4 & \\
2 times & 6 & 2.67 \\
3 times & 140 & 4.00 \\
$\quad$ o or more times & 57 & 93.33 \\
Trimester of first visit & 92 & 38.00 \\
$\quad$ First & 1 & 61.33 \\
$\quad$ Second & 150 & 0.67 \\
$\quad$ Third & 150 & 100.00 \\
Investigations & 29 & 100.00 \\
$\quad$ Blood test & 148 & 19.33 \\
Urine test & & 98.67 \\
$\quad$ Stool test & 150 & 100.00 \\
$\quad$ Ultrasound & 147 & 98.00 \\
Medicines taken & 150 & 100.00 \\
Iron & 30 & 20.00 \\
$\quad$ Albendazole & & \\
TD vaccine & & \\
Anti-malarial prophylaxis & 30 &
\end{tabular}

Table 2. Utilization of intranatal and postnatal services $(n=148)$

\begin{tabular}{lcc}
\hline Variables & Frequency & Percentage \\
\hline Delivery in health center (n=150) & 148 & 98.67 \\
Vitamin A administration & 147 & 99.32 \\
Immediate breastfeeding within 1 hour & 120 & 81.08 \\
after birth & 147 & 99.32 \\
Maternal incentives & 16 & 10.81 \\
Nyano jhola & 148 & 100.00 \\
Postnatal check-up & & \\
Frequency of PNC & 81 & 54.73 \\
Within 24 hours & 66 & 44.59 \\
Within 72 hours & 138 & 93.24 \\
Within 7 days & 133 & 89.86 \\
Within 42 days &
\end{tabular}


Regarding health education $97.97 \%$ of the respondents received health education on intake of iron tablet, and breast feeding followed by postnatal check-up (97.29\%), sexual intercourse (90.54\%), family planning (85.81\%) and danger signs $(39.86 \%)$.

\section{Table 3. Utilization of child health services}

\begin{tabular}{lcc}
\hline Child health services & Frequency & Percentage \\
\hline Inj vitamin K (n=148) & & \\
$\quad$ Yes & 8 & 5.33 \\
$\quad$ No & 2 & 1.33 \\
$\quad$ Don't know & 138 & 93.24 \\
Chlorhexidine ointment (n=150) & & \\
$\quad$ Yes & 92 & 61.33 \\
$\quad$ No & 9 & 6.00 \\
$\quad$ Don't know & 49 & 32.67 \\
Immediate breastfeeding (n=150) & 120 & 80.00 \\
Immunization (n=150) & 150 & 100.00 \\
\hline
\end{tabular}

Table 4. Utilization of maternal health services $(n=150)$

\begin{tabular}{ccc}
\hline Utilization of maternal health services & Frequency & Percentage \\
\hline Partial & 104 & 69.30 \\
Complete & 46 & 30.70 \\
\hline
\end{tabular}

Table 5. Association between respondent's socio-demographic variables and utilization of maternal health services $(n=150)$

\begin{tabular}{|c|c|c|c|c|c|}
\hline \multirow[b]{2}{*}{$\underline{\text { Variables }}$} & \multicolumn{5}{|c|}{ Utilization of MHS } \\
\hline & & Partial & Complete & $\chi^{2}$ value & $p$-value \\
\hline \multirow{3}{*}{$\begin{array}{l}\text { Age of } \\
\text { women }\end{array}$} & 20-24 years & $36(76.6 \%)$ & $11(23.4 \%)$ & 2.013 & 0.365 \\
\hline & $25-29$ years & $47(64.4 \%)$ & $26(35.6 \%)$ & & \\
\hline & $30-34$ years & $21(70 \%)$ & $9(30 \%)$ & & \\
\hline \multirow{3}{*}{$\begin{array}{l}\text { Ethnicity } \\
\text { of women }\end{array}$} & Pahadi & $20(30.4 \%)$ & $32(69.6 \%)$ & 38.460 & $<0.001$ \\
\hline & Madhesi and Tharu & $53(80.3 \%)$ & $13(19.7 \%)$ & & \\
\hline & Musalman & $31(96.9 \%)$ & $1(3.1 \%)$ & & \\
\hline \multirow[t]{2}{*}{ Religion } & Hindu & $72(63.2 \%)$ & $42(36.8 \%)$ & 8.520 & 0.004 \\
\hline & Muslim and others & $32(88.9 \%)$ & $4(11.1 \%)$ & & \\
\hline \multirow[t]{5}{*}{ Education } & Illiterate & $10(100 \%)$ & $0(0 \%)$ & 61.591 & $<0.001$ \\
\hline & Can read and write & $57(93.4 \%)$ & $4(6.6 \%)$ & & \\
\hline & Basic & $16(80 \%)$ & $4(20 \%)$ & & \\
\hline & Higher secondary & $17(50 \%)$ & $17(50 \%)$ & & \\
\hline & $\begin{array}{l}\text { Above higher } \\
\text { secondary }\end{array}$ & $4(16 \%)$ & $21(84 \%)$ & & \\
\hline \multirow[t]{5}{*}{ Occupation } & Only home maker & $29(82.9 \%)$ & $6(17.1 \%)$ & 48.764 & $<0.001$ \\
\hline & Farmer & $32(88.9 \%)$ & $4(11.1 \%)$ & & \\
\hline & Labor & $14(100 \%)$ & $0(0 \%)$ & & \\
\hline & Self-employee & $19(70.4 \%)$ & $8(29.6 \%)$ & & \\
\hline & Service holder & $10(26.3 \%)$ & $28(73.7 \%)$ & & \\
\hline
\end{tabular}

There were significant association of ethnicity, religion, education and age of marriage of women age at marriage, gravida, para, abortion or child death and number of live children with utilization of maternal health services.

Education and occupation of respondent's spouse were significantly associated with utilization of maternal health services

\section{DISCUSSION}

The study revealed that $100 \%$ of the respondents did antenatal check-up which is consistent with study ${ }^{7}$ which shows that 97\% had visited at least one antenatal check-up during their pregnancy. The study showed that $93.33 \%$ of the respondents visited four or more times for antenatal check-up and $61.33 \%$ visited $\mathrm{ANC}$ in the second trimester. The findings are not consistent with study, ${ }^{4}$ which shows $70 \%$ of the sample visited four or more times for antenatal check-up with health care providers and with the study ${ }^{8}$ which shows that $69 \%$ started ANC visits in the second trimester. The findings of the study showed that $38 \%$ of respondents had ANC visited in first trimester which is not consistent with study ${ }^{4}$ which shows twothirds of respondents have their first visit in first trimester.

Regarding investigations during pregnancy, cent percent of the respondents did blood and urine test. These findings are not consistent with study ${ }^{4}$ which shows that $76 \%$ did urine test, and $66 \%$ did blood test. The study showed that $99 \%$ of the respondents had done USG during pregnancy and 19.33\% respondents did stool test.

The findings of the study showed that, $100 \%$ of the respondents had taken iron tablet and TD vaccine in last pregnancy which are not consistent with study ${ }^{4}$ which shows $91 \%$ take iron tablets or syrup during pregnancy and $89 \%$ of women's most recent births were protected against neonatal tetanus.

The study found that $98 \%$ and $20 \%$ of the respondents had received antihelmenthic (albendazole) and anti-malarial prophylaxis. The respondents got health education during last pregnancy, nutrition $(99.33 \%)$, hygiene $(92 \%)$, cessation of smoking $(89.33 \%)$, rest and exercise $(88.67 \%)$, cessation of alcohol $(80.67 \%)$, avoid long travel $(70.67 \%)$, danger signs $(66.67 \%)$, avoidance of sexual intercourse $(54 \%)$, clothing (45.33\%) and birth preparedness (44\%).

The study revealed that $98.67 \%$ of the respondents had delivered in health centres. It is not consistent with study ${ }^{9}$ which shows $59 \%$ of women delivered their last child at health facility.

The findings of the study showed that, among 148 respondents who delivered their previous child at health facility, $99.32 \%$ received Vitamin A after delivery. The study revealed that $54.73 \%$ of the respondents had received postnatal care within 24 hours of giving birth. It is consistent with study ${ }^{10}$ shows $54 \%$ of the women revived postnatal care within 48 hours of giving birth.

The findings of the study found that respondents received health education on rest and exercise $(44.59 \%)$, danger sign of postnatal mother $(42.57 \%)$, newborn care $(41.89 \%)$ and danger signs of newborn $(39.86 \%)$. The study found that $69.3 \%$ of the respondents partially utilized maternal health services and only $30.7 \%$ of the respondents utilized complete 
maternal health services in their previous pregnancy.

Regarding child health services, the study found that Chlorhexidine ointment was applied on $61.33 \%$ of the newborn and $80 \%$ of respondents initiated breastfeeding within 1 hour after birth. The findings are not consistent with study $^{4}$ which shows that Chlorhexidine was applied on $39 \%$ of newborns and $55 \%$ of children are breast fed within one hour.

The study showed that $5.33 \%$ of newborns received injection vitamin $\mathrm{K}$, but $93.24 \%$ of respondents were not aware of administration of injection vitamin $\mathrm{K}$ to their newborn.

The study revealed that religion $(p<0.004)$, education $(p<0.001)$, and number of live children $(p<0.035)$ are significantly associated with utilization of maternal health services. It is consistent with the study ${ }^{11}$ which shows religion, literacy level and parity of respondents were significantly associated with utilization of maternal health services.

The study revealed that ethnicity $(p<0.001)$, occupation ( $p<$ $0.001)$, age at marriage $(p<0.001)$, gravida $(p<0.003)$, para $(p<0.009)$, abortion or child death $(p<0.005)$ and number of live children $(p<0.035)$ were significantly associated with utilization of maternal health services. Similarly, education $(p<00.001)$ and occupation $(p<0.001)$ of respondent's spouse are significantly associated with utilization of maternal health services.

\section{CONCLUSION}

On the basis of findings, it is concluded that more than twothirds of women partially utilize maternal health services. Cent percentage of women visit health canters for antenatal check-up at least once, majority of the women have done four or more ANC visits and nearly two-thirds of women visit in second trimester of previous pregnancy. The women receive less health education on danger signs of pregnancy, avoidance of sexual intercourse, clothing and birth preparedness during antenatal visit. Almost all women delivered in health facility and receive vitamin A capsule. More than half of the women receive postnatal care within 24 hours of giving birth. Less than half of the women receive health education on rest and exercise, danger signs of mother and newborn and newborn care during postnatal period.

Out of five, four newborn are breast fed within one hour of birth and chlorhexidine ointment was applied on more than three-fifth of newborns. Cent percentage of newborns receive BCG vaccine but the most of women are not aware of administration of injection vitamin $\mathrm{K}$ to their newborns. It is further concluded that, ethnicity, religion, education, occupation, age at marriage, gravida, parity, abortion and child death, number of live children are statistically significant with utilization of maternal health services. Similarly, spouse education and occupation are statistically significant with utilization of maternal health services.

\section{IMPLICATIONS}

The findings of the study might be helpful to nurses and health personnel to give more emphasis of health education regarding birth preparedness, danger signs of pregnancy, newborn care, danger signs of postnatal mother and newborn. The findings might be helpful to provide baseline information for further research.

\section{LIMITATIONS}

The study was conducted by using non probability purposive sampling technique, it lacks external validity and was conducted in hospital setting of urban area so, and it cannot generalize in rural areas.

\section{RECOMMENDATIONS}

It is recommended that, nurses and health personnel should provide health education focusing on birth preparedness, danger signs of pregnancy, newborn care, danger signs of postnatal mother and newborn.

Nurses should clearly inform to postnatal mothers regarding administration of injection vitamin $\mathrm{K}$ and application of chlorhexidine ointment to newborn.

\section{ACKNOWLEDGEMENT}

Researchers deeply express their heartfelt thanks to all mothers who participated in the study for immense support and cooperation. Researchers express their deep and sincere gratitude to all those experts for their valuable judgment, constructive feedback and enlightening suggestions throughout the study.

\section{REFERENCES}

1. World Health Organization. Trends in maternal mortality 2000 to 2017: estimates by WHO, UNICEF, UNFPA, World Bank Group and the United Nations Population Division.

2. World Health Organization. Maternal mortality fact sheet no. 348. 2015. Available from: $<$ a target $="$ _blank" href $="$ http:// www. who. int/mediacentre/factsheets/fs348/en/"

3. Tey NP, Lai SL. Correlates of and barriers to the utilization of health services for delivery in South Asia and Sub-Saharan Africa. The Scientific World Journal. 2013 Oct; 2013.

4. NDHS, 2016 (Ministry of Health, Nepal; New ERA; and ICF. 2017. 2016 Nepal Demographic and Health Survey Key Findings. Kathmandu, Nepal: Ministry of Health Nepal.

5. WHO. Maternal health 2016. Available from: https://www. who.int/health-topics/maternal-health\#tab=tab_1

6. Rutaremwa G, Wandera SO, Jhamba T, Akiror E, Kiconco A. Determinants of maternal health services utilization in Uganda. BMC Health Services Research. 2015 Dec 1;15(1): 271. 
7. Mallick L, Dontamsetti T, Pullum TW, Fleuret J. Using the Uganda Demographic and Health Surveys from 2011 and 2016 to assess changes in Saving Mothers, Giving Life intervention districts. Journal of Global Health Reports. 2019;3:2019.

8. Yar'Zever IS, Said IY. Knowledge and barriers in utilization of maternal health care services in Kano state, Northern Nigeria. Eur J Biol Med Sci Res. 2013 Mar;1(1):1-4.

9. Ndugga P, Namiyonga NK, Sebuwufu D. Determinants of early postnatal care attendance: analysis of the 2016 Uganda demographic and health survey. BMC Pregnancy \& Childbirth. 2020 Dec;20(1):1-4.

10. Alemayeh H, Assefa H, Adama Y. Prevalence and factors associated with postnatal care utilization in Abi-Adi town, Tigray, Ethiopia: A cross sectional study. IJPBSF International Journal of Pharmaceutical and Biological Sciences Fundamentals. 2014;8(01):23-35.

11. Deepak C, Jauhari N, Dhungana H. A study on utilization of maternal health services and factors influencing the utilization in urban slums of Lucknow. International Journal of Medicine and Public Health. 2018;8(2):77-81. 